\title{
Molecular Cytogenetic Evaluation of Xq Deletion Mosaicism in a Case of Primary Amenorrhea
}

\author{
Babu Rao Vundinti , Lily Kerketta , Seema Korgaonkar, Kanjaksha Ghosh and Dipika Mohanty \\ Institute of Immunohaematology (ICMR) 13th floor, New Multistoryed Building, \\ K.E.M Hospital Campus, Parel, Mumbai 400 012, Maharashtra, India
}

KEYWORDS Sex chromosome; structural abnormalities; in situ hybridization; molecular cytogenetics

\begin{abstract}
The $X$ chromosome contains determinants necessary to assure normal ovarian function and normal statural growth. Deletions of proportions of the $\mathrm{X}$ chromosome have been reported in a large number of patients, most which are isolated. We report a mosaic long arm deletion of $\mathrm{X}$ chromosome (Xq-) in a women with primary amenorrhea. Chromosomal analysis using GTG-banding showed two cell lines $(45, \mathrm{X} / 46, \mathrm{X}, \mathrm{del}(\mathrm{X}))$. The Fluorescence in situ hybridization study helped to detect the breakpoint at q13.3 region of the $\mathrm{X}$ chromosome and also enable to detect low grade third cell line with 47,XX,del(X)(q13.3). Hence, molecular cytogenetic methods are essential to detect low level mosaicism which is important in better counselling .
\end{abstract}

\section{INTRODUCTION}

Primary amenorrhea frequently have impaired gonadal function and an end result of large number of clinical entities. It could occur as a result of congenital malformations, metabolic dearrangements, selective anterior pituitary failure, genetic defects and other malignant tumours. Primary gonadal failure has been reported in these women in association with normal and abnormal chromosomal complements (McDonough 1978; Reinodollar et al.1981).We report a mosaic 45, X/46, X, (delX) (q13.3) /47, $\mathrm{XX}, \operatorname{del}(\mathrm{X})(\mathrm{q} 13.3)$ karyotype in a case of primary amenorrhea .

\section{CASE REPORT}

A 26-year-old married women was referred for cytogenetic analysis because of primary amenorrhea. She was 1 st born to nonconsanguineous parents. Clinical examination revealed that her height was $155 \mathrm{~cm}$, weight 50 $\mathrm{kg}$ and $\mathrm{arm}$ span $150 \mathrm{~cm}$. She had abscence of secondary sexual characters, lack of axillary and pubic hair, cubitus valgus and under developed breast. Both her parents and sisters were phenotypically normal. Ultrasonography of pelvis revealed hypoplastic ovaries and uterus.

Corresponding Author: Dr. V. Babu Rao, Department of Cytogenetics, Institute of Immunohaematology (ICMR) 13th floor, New Multistoryed Building, K.E.M Hospital Campus, Parel, Mumbai 400 012, Maharashtra, India

E-mail: vbaburao@hotmail.com
The follicular stimulating hormone (FSH) and leutinising hormone (LH) hormonal levels were high (FSH-31.5mIU/ml, LH-31.8mIU/ml) compared to normal females (FSH-0-13mIU/ml, LH-0-25mIU/ml).

\section{CYTOGENETICS}

Chromosomal analysis using GTG-banding revealed $45, \mathrm{X} / 46, \mathrm{X}$, del(X) karyotype. Fluorescence in situ hybridization (FISH) study was carried out to detect accurate break points on X chromosome. A Xq13.3 locus specific probe (bA130O19) and partial chromosome paint (PCP-092 from somatic hybrids) were labelled with $\mathrm{Cy} 3$ and hybridized on metaphases using standard procedure. The slides were stained with DAPI and images were collected using a fluorescence microscope equipped with a cooled CCD camera were modified using adobe photoshop.FISH results showed 45, X/46, Xdel (X) (q13.3) / 47, XX, del(q13.3) karyotype (Fig.a,b,c\&d) .

\section{DISCUSSION}

Women with 45,X cell line, with or without mosaicism generally manifest gonadal failure. About $90 \%$ of patients with a $45, X$ cell line present with the lack of pubertal development and no menarche (Layman and Reindoller 1994). In our case, the women had three cell lines i.e monosomy X, Xq deletion with 46 and 47 chromosome complements . Chromosomal 


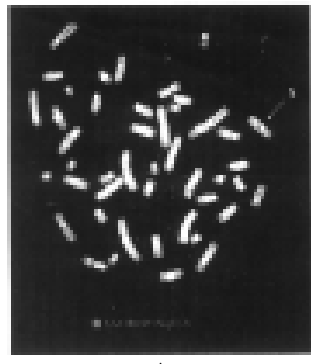

A

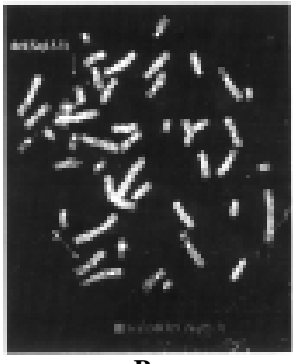

B

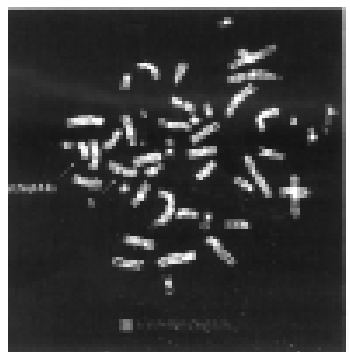

C

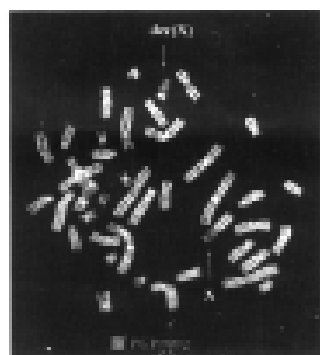

D

Fig. 1. FISH showing (A) metaphase with monosomy $X$ q 13.3 break point, (B) metaphase with XXq-break point 13.3, (C) metaphase with XXXq-breakpoint 13.3 and (D) partial chromosome painting showing partial long arm deletion of $X$ chromosome.

anaysis using conventional GTG-banding revealed two cell lines $(45, \mathrm{X} / 46, \mathrm{X}, \mathrm{del}(\mathrm{X})(\mathrm{q} 13.3)$ and when FISH study was carried out, interestingly the third cell line was detected with 47,XXXq-chromosomal complements. Deletions on $\mathrm{X}$ chromosome have been reported in a large number of patients, most of which are isolated . Deletion at Xp11 region result in ovarian failure in about half of women with menstrual function in the other half (Simpson and Rajkovic 1999). Even in those with normal menstruation, fertility is rare. When the deletion on the $\mathrm{X}$ chromosome is more distal, the phenotype is generally milder , although secondary amenorrhea is common(Skibsted et al. 1984). Most women with $\mathrm{Xp}$ deletion are short, regardless of their ovarian function indicating that other statural determinant genes probably lie within these region (Simpson and Rajkovic 1999). In the present case despite absence of long arm of $\mathrm{X}$ chromosome patient had normal stature suggests that the presence of short arm of X chromosome maitains the stature of the affected. Deletion involving the long arm of $\mathrm{X}$ chromosome generally result in ovarian failure if they involve the proposed critical region $\mathrm{Xq} 13-\mathrm{q} 26$ (Goldman et al. 1982) . In our case ,patient presented with primary amenorrhea might be due to loss of $\mathrm{Xq}$ critical region. However, as the patient had cell line with two normal $X$ chromosomes, the chance of fertility can be improved through hormonal replacement therapy

The molecular mechanisms (s) responsible for gonadal failure with $\mathrm{X}$ chromosome deletions could involve the loss of putative ovarian determinant gene(s) necessary to be present in two copies during ovarian development. With an $\mathrm{X}$ chromosome deletion, the dosage of a normal gene is decreased and gonadal failure could ensue since reactivation of the previously inactivated X chromosomes occurs during oogenesis (Layman 1997; Simpson and Rajkovic 1999). Deleted ovarian determinant gene(s) probably increase follicular atresia. It also possible that partial $\mathrm{X}$ chromo-some deletions might affect mitosis or meiosis leading to enhanced follicular atresia. In conclu-sion, FISH study is essential to detect low level mosaicism with normal $\mathrm{X}$ chromosomes in such patients for the apropriate counseling .

\section{ACKNOWLEDGEMENTS}

Authors are thankful to Prof. Rocchi, University of Bari, Italy for providing BAC clones and partial chromosome paints.

\section{REFERENCES}

Goldman B, Polani Pe, Daker MG, Angell RR 1982. Clinical and cytogenetic aspects of X - chromosome deletions. Clin Genet, 21: 36-52.

Layman LC, Reindollar RH 1994 . The diagnosis and treatment of pubertal disorders. Adolesc Med: State of the Art Reviews, 5: 37-55

Layman LC 1997. Familial ovarian failure. In: RA Lobo (Ed): Primenopause. NY: Springer-Verlag, Ch 6, pp. 46-77.

McDonough 1978. Amenorrhea-etiologic approach to diagnosis. Fertl Steril, 30: 1-5.

Reindollar RH, Byrd JR, McDonough PG 1981. Delayed sexual development: A study of 252 patients. Am J Obstet Gynecol, 140: 371-76.

Simpson JL, Rajkovic A 1999. Ovarian differentiation and gonadal failure. Am J Med Genet, 89: 186-200.

Skibsted L,Westh H, Niebuhr E 1984. X long -arm deletions. A review of non-mosaic cases studied with banding techniques. Hum Genet, 67: 1-5. 